\title{
The management of hyperphosphatemia by lanthanum carbonate in chronic kidney disease patients
}

This article was published in the following Dove Press journal: International Journal of Nephrology and Renovascular Disease 27 May 2012

Number of times this article has been viewed

\author{
Takashi Shigematsu \\ Yuri Nakashima \\ Masaki Ohya \\ Koichi Tatsuta \\ Daisuke Koreeda \\ Wataru Yoshimoto \\ Shintaro Yamanaka \\ Toshifumi Sakaguchi \\ Yoshiyuki Hanba \\ Toru Mima \\ Shigeo Negi \\ Division of Nephrology, Department \\ of Internal Medicine, Wakayama \\ Medical University, Wakayama City, \\ Wakayama, Japan
}

\begin{abstract}
Hyperphosphatemia has been shown to be involved not only in the onset and progression of secondary hyperparathyroidism but also in vascular calcification. In addition, it influences the clinical course of patients with chronic kidney disease. Phosphate (Pi) binder is required in the management of hyperparaphosphatemia, because dietary Pi restriction and Pi removal by hemodialysis alone are insufficient. Lanthanum carbonate, a powerful Pi binder, has a similar effect to aluminum hydroxide in reducing serum Pi levels. As it is excreted via the liver, lanthanum carbonate has an advantage in patients with renal failure. The effect of lanthanum carbonate on serum Pi levels is almost two times higher than that of calcium (Ca) carbonate, which is commonly used. Lanthanum carbonate and Ca carbonate have an additive effect. Worldwide, there is 6 years worth of clinical treatment data on lanthanum carbonate; however, we have 3 years of clinical use in Japanese patients with hyperphosphatemia. No serious side effects have been reported. However, the most important concern is bone toxicity, which has been observed with use of aluminum hydroxide. For this study, clinical research involved analysis of bone biopsies. Although osteomalacia is the most noticeable side effect, this was not observed. Both the high- and the low-turnover bone disease concentrated into a normal bone turnover state. However, as the authors have less than 10 years' clinical experience with lanthanum carbonate, patients should be monitored carefully. In addition, it is necessary to demonstrate whether potent treatment effects on hyperphosphatemia improve the long-term outcome.
\end{abstract}

Keywords: phosphate binder, end-stage renal disease (ESRD), fibroblast growth factor 23 (FGF23), vascular calcification

\section{Introduction}

In patients with chronic kidney disease (CKD), as renal function declines, hyperphosphatemia progresses with low urinary excretion of phosphate (Pi). Hyperphosphatemia has been shown to be an important factor in the onset and progression of secondary hyperparathyroidism. In a recent clinical study, hyperphosphatemia was shown to be a strong risk factor for cardiovascular events in patients with $\mathrm{CKD},{ }^{1}$ and hyperphoshatemia has also been known to cause vascular calcification. ${ }^{2}$ Because hyperphosphatemia is a significant mortality risk factor in patients with $\mathrm{CKD},{ }^{3,4}$ the management of hyperphosphatemia is an important therapeutic target in CKD treatment.

\section{Therapeutic strategy for hyperphosphatemia}

Treatment for hyperphosphatemia in patients with CKD includes the following three modalities: diet therapy (ie, Pi restriction), hemodialysis (HD) (blood purification), and 
pharmacological intervention. Although very effective, diet therapy can lead to malnutrition if continued for a long time, and dialysis therapy alone is not enough to effectively control hyperphosphatemia, with Pi removal of only $2400 \mathrm{mg} /$ week in CAPD patients and $3000 \mathrm{mg} /$ week in HD patients with 3 times a week sessions (Figure 1). Accordingly, pharmacological therapy (Pi binder prescription) is an inevitable option.

Although many Pi binders have been used in clinical practice, there is no ideal Pi binder as yet available. Criteria for an ideal Pi binder include (1) good compliance (easy to take the drug); (2) powerful reducing power of serum Pi; (3) no evidence of accumulation; and (4) no serious side effects. In 1992, the powerful Pi binder aluminum hydroxide was contraindicated in uremic patients in Japan because of its bone and central nervous system (CNS) toxicity. ${ }^{5}$ Since then, calcium (Ca)-containing Pi binders have been prescribed widely, although they have hypercalcemia as a major adverse effect. However, aluminum hydroxide is still used as a Pi binder in European countries and it is also used, albeit on a limited basis, in the United States (US).

As a non-Ca/non-aluminum $\mathrm{Pi}$ binder, a synthetic polymer of sevelamer hydrochloride has gradually been applied in clinical practice. The sevelamer hydrochloride can work not only as a non-Ca, non-aluminum Pi binder but also as an effective inhibitor for vascular calcification. Chertow et $\mathrm{al}^{6}$ have clearly shown the inhibitory effect on coronary and aortic calcification of sevelamer with reduction of $\mathrm{CaPi}$ product. However, side effects in the digestive system such as constipation have caused low compliance in Japanese dialyzed patients. In addition, sevelamer hydrochloride exacerbates metabolic acidosis due to the release of chloride ions in the intestinal cavity. ${ }^{7}$ The next sevelamer without deterioration of metabolic acidosis is sevelamer carbonate, and this may be better for CKD patients with hyperphosphatemia prior to dialysis therapy. ${ }^{8}$ Unfortunately, sevelamer carbonate has not been developed in the Japanese market as another non-Ca/nonaluminum Pi binder, and it is still not available in Japan.

Lanthanum carbonate was finally approved in Japan as a Pi binder for use in patients on dialysis in March 2009. This product was developed as a chewable tablet able to be taken without water, making it suitable for dialyzed patients. This article will discuss the novel Pi binder with a particular focus on lanthanum carbonate.

\section{Lanthanum carbonate therapy for hyperphosphatemia Chemical structure and pharmacological action of lanthanum carbonate}

Lanthanum is a trivalent rare earth element with an atomic number of 57. The molecular formula of lanthanum carbonate is $\mathrm{La}_{2}\left(\mathrm{CO}_{3}\right)_{3} \cdot 4 \mathrm{H}_{2} \mathrm{O}$ and the drug molecular weight is 529.9. After oral administration, lanthanum carbonate creates a strong insoluble bond with $\mathrm{Pi}$ and is excreted in the feces. In vitro studies, more than $97 \%$ of added phosphorus ( $\mathrm{pH} 3$ and $\mathrm{pH} 5$ ) was removed and, similarly to aluminum hydroxide, lanthanum carbonate demonstrated better absorption than $\mathrm{Ca}$ carbonate. ${ }^{9}$ Lanthanum carbonate is water insoluble, and its intestinal absorption is extremely low, between $0.0007 \%$ (rats) and $0.00005 \%$ (dogs). Results showed $99.4 \%$ of the oral

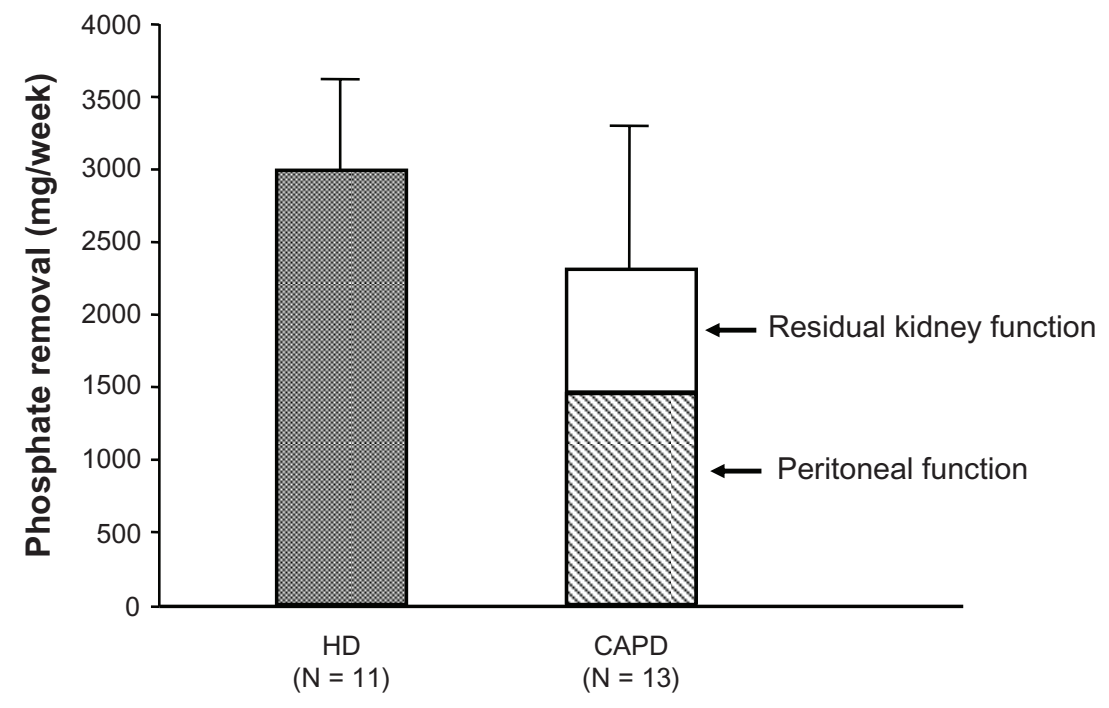

Figure I Results of weekly phosphate (Pi) removal by hemodialysis (HD) and continuous ambulatory peritoneal dialysis (CAPD) procedures. The amount of Pi removed weekly by HD sessions three times a week was $2388-3006 \mathrm{mg} /$ week in eleven patients. The removal by CAPD with residual kidney function was $2300 \pm$ II 3 mg/week in 13 patients, less than that by HD. These amounts of Pi removed by conventional dialysis therapy alone are insufficient, and this is why a Pi binder is used. 
lanthanum carbonate dose was recovered in the feces. When lanthanum chloride was intravenously administered to rats, $96.9 \%$ of lanthanum was recovered in the feces. Accordingly, the major excretion route for lanthanum is via the bile, which is an advantage for patients with renal failure. ${ }^{10}$ In Europe, this product was approved as a Pi binder in Sweden in March 2004. It was approved in the US in April 2005, and Japanese approval was granted in April 2009. Since then, the product has been used in clinical settings.

\section{Phosphorus-reduction effect of lanthanum carbonate}

The therapeutic effect of lanthanum carbonate for hyperphosphatemia has been demonstrated in several clinical studies. ${ }^{9,11}$ Joy et $\mathrm{al}^{11}$ reported more significant effect on hyperphosphatemia with lanthanum carbonate than with $\mathrm{Ca}$ carbonate through a randomized, double-blind study in HD patients. This study consisted of a washout period for premedication with Ca products (1-3 weeks); a 6-week dose adjustment period (the initial dose of lanthanum carbonate was $750 \mathrm{mg} /$ day and was increased to a maximum of $3000 \mathrm{mg}$ /day); and a 4-week, fixed-dose, double-blind period (comparison between Ca carbonate and lanthanum carbonate groups). During the course of the study, the serum Pi level in the lanthanum carbonate group $(\mathrm{n}=49)$ was $7.69 \mathrm{mg} / \mathrm{dL}$ in the washout period and $5.49 \pm 1.48 \mathrm{mg} / \mathrm{dL}$ in the dose adjustment period; at completion of the double-blind study period, it was $5.94 \pm 1.65 \mathrm{mg} / \mathrm{dL}$ and was thus controlled at below $6.0 \mathrm{mg} / \mathrm{dL}$. On the other hand, in the comparator group $(n=44)$, serum Pi level before and after the double-blind period increased from $5.62 \pm 1.61 \mathrm{mg} / \mathrm{dL}$ to $7.85 \pm 1.96 \mathrm{mg} / \mathrm{dL}$. The serum Pi level in the comparator group was significantly higher than that in the lanthanum carbonate group.

In Japan, the authors reported the serum Pi control effect of lanthanum carbonate in a randomized, double-blind, placebo-controlled, multicenter, dose-dependent study in HD patients. ${ }^{12}$ After a 3-week washout period, patients were randomly allocated either to a placebo group or to lanthanum carbonate groups (four groups: $750 \mathrm{mg} /$ day, $1500 \mathrm{mg} /$ day, $2250 \mathrm{mg} /$ day, and $3000 \mathrm{mg} /$ day) and a 6-week observation period was provided. Serum concentrations of Pi were reduced in a dose-dependent manner up to $2250 \mathrm{mg}$ /day of lanthanum carbonate and its effect was observed within 1 week after initiation of oral lanthanum carbonate administration (Figure 2). Serum Ca was not significantly changed during the whole treatment period. As a result, it was concluded that the therapeutic dose range suitable for HD patients with hyperphosphatemia is $1500-2250 \mathrm{mg} /$ day, and $750 \mathrm{mg} /$ day is recommended as the initial dose. ${ }^{12}$ In addition, the treatment effect of lanthanum carbonate on hyperphosphatemia in continuous ambulatory peritoneal dialysis patients was reported. In this patient population, 750-1500 mg/day or a smaller dose range than in HD patients is considered optimal. ${ }^{13}$ Successful treatment for hyperphosphatemia can achieve the reduction of $\mathrm{CaPi}$ product. As one of the risk factors for vascular calcification, this $\mathrm{CaPi}$ product is mainly determined by serum $\mathrm{Pi}$ level, but not by $\mathrm{Ca}$ level (Figure 3A and B). ${ }^{14}$ The lanthanum carbonate without $\mathrm{Ca}$ as a $\mathrm{Pi}$ binder may inhibit vascular

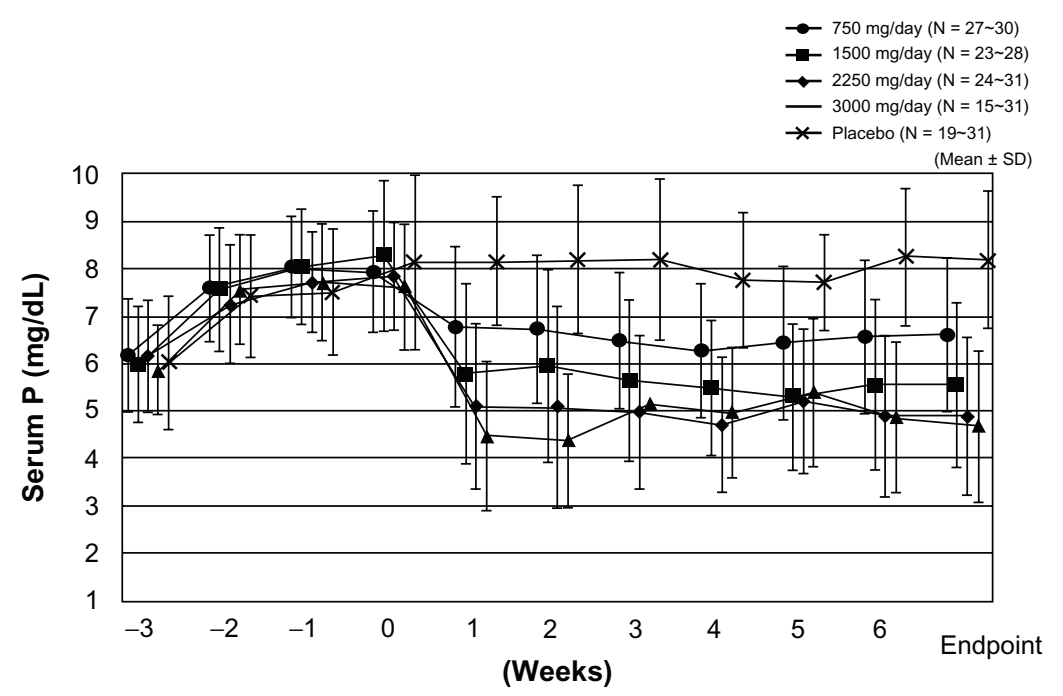

Figure 2 Lanthanum carbonate effectively controls serum phosphate $(\mathrm{Pi})$ in a dose-dependent manner. The result was obtained from the prospective, randomized, doubleblind, placebo-controlled, multicenter study on Japanese hemodialysis patients. Changes in serum Pi level from week -3 to week 6 are presented for each treatment group, together with the last observation carried forward as the endpoint. Lanthanum carbonate effectively controls serum Pi without affecting serum calcium level. The magnitude of serum Pi level reduction is greater at higher dosages, but it reached a plateau at a daily dose of $2250 \mathrm{mg}$.

Note: Copyright (c) 201I. Reproduced with permission from John Wiley and Sons. Shigematsu T; for Lanthanum Carbonate Research Group. Lanthanum carbonate effectively controls serum phosphate without affecting serum calcium levels in patients undergoing hemodialysis. Ther Apher Dial. 2008; I2(I):55-6I.'2 
A

$$
r^{2}=0.229
$$

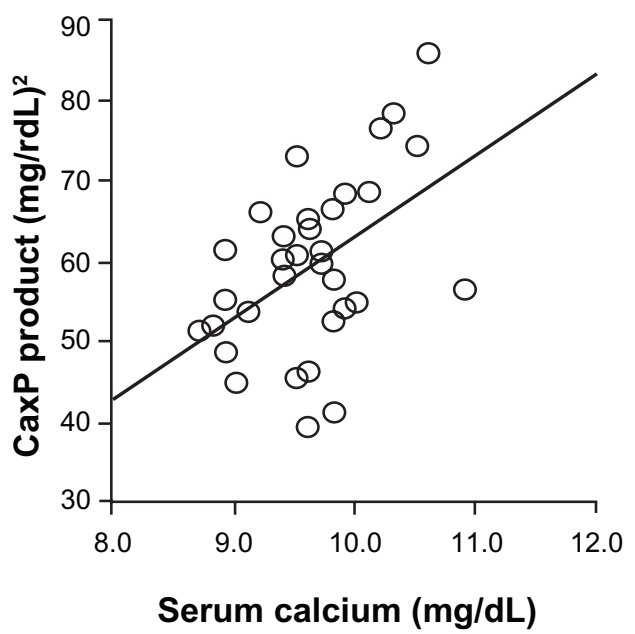

B

$$
\begin{aligned}
& Y=10.476-5.155, r^{2}=0.914 \\
& P<0.001
\end{aligned}
$$

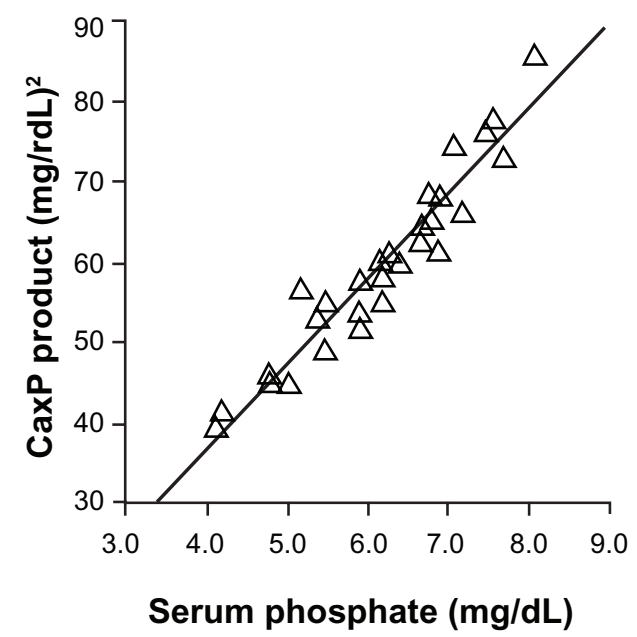

Figure 3 Correlation between the calcium ( $\mathrm{Ca}$ )-phosphate $(\mathrm{Pi})$ product and the serum $\mathrm{Ca}$ or serum $\mathrm{Pi}$ concentration. The serum $\mathrm{Pi}$ level was the significant factor in determining CaPi product. The CaPi product is mainly determined by the Pi concentration and is closely correlated with the serum $\mathrm{Pi}\left(\mathrm{Y}=10.476-5.155, \mathrm{r}^{2}=0.914\right)$, but not with the serum $\mathrm{Ca}\left(\mathrm{r}^{2}=0.229\right)$.

Note: Reproduced from Shigematsu T, Kono T, Satoh K, et al. Phosphate overload accelerates vascular calcium deposition in end-stage renal disease patients. Nephrol Dial Transplant. 2003; 18 Suppl 3:iii86-iii89, 14 with permission from Oxford University Press.

calcification in CKD patients. Further prospective interventional study is required to prove this inhibitory effect.

One study of lanthanum carbonate treatment was performed for comparison with $\mathrm{Ca}$ carbonate or sevelamer hydrochloride. ${ }^{15}$ In this double-blind, comparative study with Ca carbonate, the serum Pi level was well controlled in both the lanthanum carbonate group and the $\mathrm{Ca}$ carbonate group during the 8-week treatment period. ${ }^{15}$ The therapeutic effect was almost the same. It was concluded that since lanthanum carbonate is not associated with hypercalcemia, it is advantageous for patients on HD (Figure 4A and B). The dosage of lanthanum carbonate was approximately half that of the $\mathrm{Ca}$ carbonate dosage (Figure 4C). The treatment effect on hyperphosphatemia was approximately two times greater with lanthanum carbonate than with $\mathrm{Ca}$ carbonate. In addition, in a randomized, crossover study with sevelamer hydrochloride, the Pi level was reduced in both groups and in the intentionto-treat analysis. There was no significant difference in the serum Pi at 4 weeks between the two groups. ${ }^{16}$

Recent studies in Europe ${ }^{17,18}$ and the US ${ }^{19,20}$ have investigated long-term treatment with lanthanum carbonate over 6 years. According to these studies, the decreased serum Pi level and $\mathrm{CaPi}$ products were maintained during the observation period. After 6 years, serum Pi level was maintained within a range of $4.5-6.5 \mathrm{mg} / \mathrm{dL}$ and there were no significant side effects known. ${ }^{18}$ In Japan, the authors have reported results of 3 years of long-term lanthanum carbonate treatment. ${ }^{21}$ Serum Pi level and CaPi product were reliably maintained for 3 years and treatment was continued without significant side effects (Figure 5A and B). However, the dose reduction of $\mathrm{Ca}$ carbonate prescription may induce elevation of the parathyroid hormone (PTH) (Figure 5C). This PTH elevation should be monitored carefully for a long time.

\section{Safety and side effects of lanthanum carbonate}

Lanthanum carbonate is a metallic salt that is not metabolized in vivo. Accordingly, there is concern about in vivo accumulation, as with aluminum products. A lot of evidence, including from animal and clinical studies, has been accumulated on this point. In a comparative study with Ca carbonate in patients with renal osteodystrophy on $\mathrm{HD}^{22}$ a bone biopsy was conducted before and 1 year after treatment. There was no progression to osteomalacia or adynamic bone disease observed in the lanthanum carbonate group, unlike in cases with aluminum hydroxide. In the same study, histomorphometric parameters of bone turnover focused on basically normal bone turnover. Malluche et $\mathrm{al}^{23}$ reported bone biopsy and bone mineral density results in a randomized comparative study with a conventional Pi binder before and after 1 and 2 years of lanthanum treatment. From this study, there was no significant difference between the two groups 
A

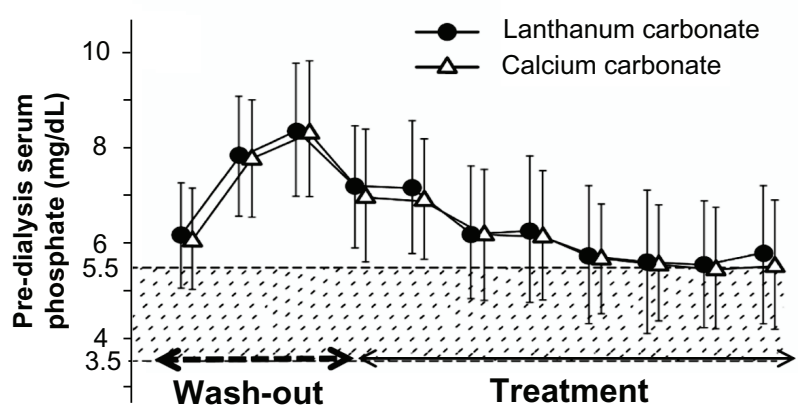

B

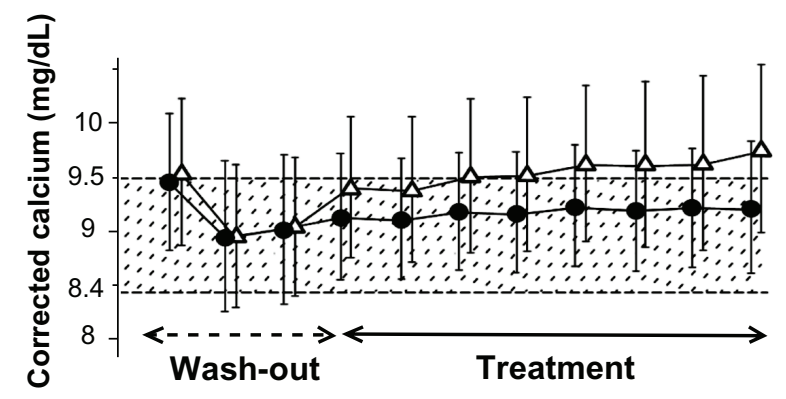

C

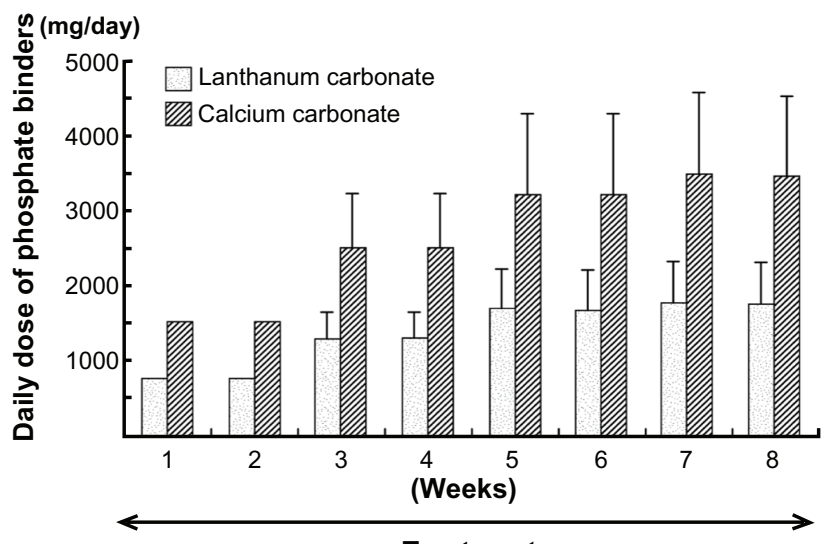

Treatment

Figure 4 Prospective, randomized, double-blind, multicenter comparative study between lanthanum carbonate and calcium $(\mathrm{Ca})$ carbonate as phosphate $(\mathrm{Pi})$ binder in hemodialysis patients with hyperphosphatemia. In the lanthanum carbonate group, the mean serum Pi level decreased from $8.35 \mathrm{mg} / \mathrm{dL}$ at baseline to $5.78 \mathrm{mg} / \mathrm{dL}$ at week 5 , and the serum $\mathrm{Pi}$ level was maintained up to the last visit. (A) A similar decrease in serum $\mathrm{Pi}$ level was also observed in the $\mathrm{Ca}$ carbonate group. During the double-blind period, the corrected serum $\mathrm{Ca}$ levels in the Ca carbonate group gradually increased, while those in the lanthanum carbonate group were relatively constant. (B) The daily doses of lanthanum carbonate became relatively constant during the last 4 weeks. At the last visit, the daily doses of lanthanum carbonate and Ca carbonate were 1725.7 and $3430.4 \mathrm{mg} /$ day, respectively (C).

Note: Reproduced from Shigematsu T; Lanthanum Carbonate Research Group. Multicenter prospective randomized, double-blind comparative study between lanthanum carbonate and calcium carbonate as phosphate binders in Japanese hemodialysis patients with hyperphosphatemia. Clin Nephrol. 2008;70(5):404-410,15 with permission from Dustri-Verlag Dr Karl Feistle GmbH and Co KG.

at 1 year. However, at 2 years, the lanthanum carbonate group was significantly improved in bone density compared with the conventional Pi binder group. In Japan, the authors also reported the results of a biopsy after 3 years of lanthanum carbonate treatment. In high-turnover bone disease, the bone turnover was returned. On the other hand, the bone turnover was stimulated in patients with low-turnover bone disease. Therefore, bone turnover was concentrating into a normal bone turnover state (Figure 6). ${ }^{24}$

Lanthanum carbonate did not show toxicity on osteoblast in animal bone biopsy experiments using renal failure rats. However, whether there are adverse effects in humans is still to be determined..$^{25}$ Next, as CNS toxicity has also been a concern with aluminum as a Pi binder, a randomized study to evaluate the effects of lanthanum carbonate on cognitive function in comparison with the standard treatment in HD patients was achieved. After 2 years of observation, the decline of cognitive function with lanthanum carbonate was comparable with the standard treatment. No evidence of CNS toxicity was demonstrated. ${ }^{26}$ In addition, since lanthanum carbonate is excreted via bile, accumulation in the liver and hepatotoxicity, which are not observed with aluminum products, were investigated. Slatopolsky et $\mathrm{al}^{27}$ reported that lanthanum accumulated in the liver in a study using renal failure rats. In subsequent investigations, as lanthanum was a locally present lysosome in the liver and was excreted via bile, no hepatotoxicity was observed. ${ }^{28,29}$ In addition, there was no liver toxicity in HD patients treated with lanthanum carbonate for 6 years' long-term follow-up. ${ }^{18}$

\section{Other effects of lanthanum carbonate}

Orally disintegrating lanthanum carbonate tablets have good adherence in patients through powerful hyperphosphatemia control activity similar to that of aluminum hydroxide, the most powerful Pi binder. There are several other noteworthy effects of lanthanum carbonate.

\section{Medical economic effects}

The use of aluminum hydroxide is prohibited in Japan for patients under dialysis therapy. Therefore, the effect of lanthanum carbonate in reducing the Pi level is the strongest when compared with other Pi binders. The favorable medical economic effects of lanthanum carbonate have been reported in second-line therapy for hyperphosphatemia as a risk factor for patient mortality, using quality-adjusted life years as a novel parameter. ${ }^{30}$

\section{The reduction effect of serum fibroblast growth factor 23}

In HD patients, high serum concentrations of fibroblast growth factor 23 (FGF23) are reported as an independent risk factor for patient mortality. ${ }^{31}$ Serum FGF23 is reduced independent of PTH by the concomitant therapy with lanthanum 

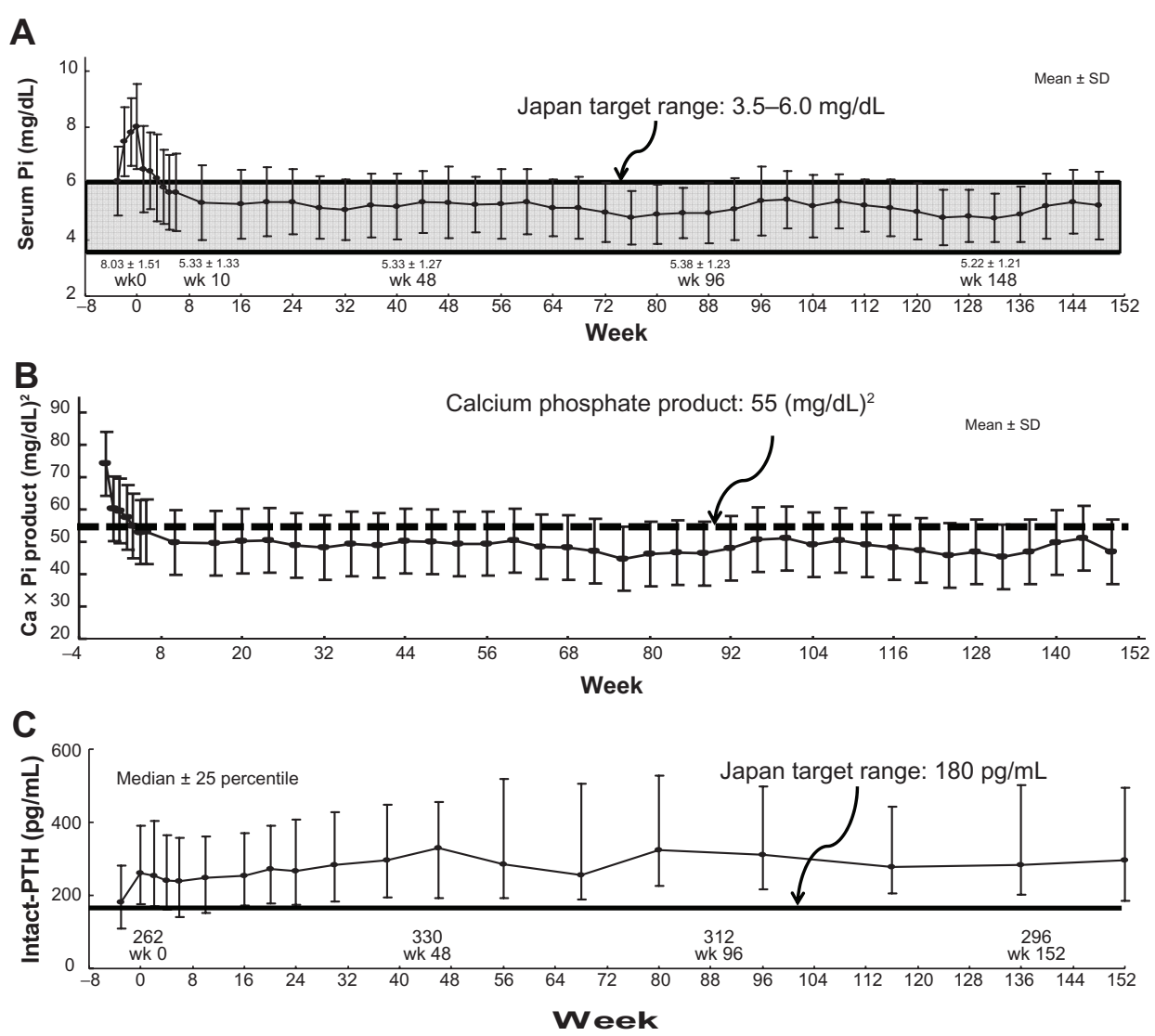

Figure 5 Clinical effects of 3-year extension study of lanthanum carbonate therapy in Japanese hemodialysis patients. (A) The mean serum phosphate ( $\mathrm{Pi}$ ) level was $8.03 \pm 1.51 \mathrm{mg} / \mathrm{dL}$ at baseline, and it decreased to $5.33 \pm 1.27 \mathrm{mg} / \mathrm{dL}$ and $5.33 \pm 1.04 \mathrm{mg} / \mathrm{dL}$ after I year and 3 years of treatment, respectively. The mean reduction of Pi from baseline was within the range of $-1.5 \mathrm{I} \pm 1.48 \mathrm{mg} / \mathrm{dL}$ in week I $(95 \% \mathrm{Cl}:-1.76,-1.27)$ to $-3.08 \pm 1.76 \mathrm{mg} / \mathrm{dL}$ in week $128(95 \% \mathrm{Cl}:-3.69,-2.47)$. (B) The calcium (Ca)- $\mathrm{Pi}$ product has been well controlled below $55.0(\mathrm{mg} / \mathrm{dL})^{2}$ dependent on serum Pi level. (C) On the other hand, the intact parathyroid hormone (PTH) level was elevated overall and then stable throughout the treatment period, with a median value of $262.0 \mathrm{pg} / \mathrm{mL}$ at baseline and $283.8 \mathrm{pg} / \mathrm{mL}$ at 3 years.

Note: From Shigematsu' ${ }^{21}$ with permission from Springer Japan and the Japanese Society of Nephrology.

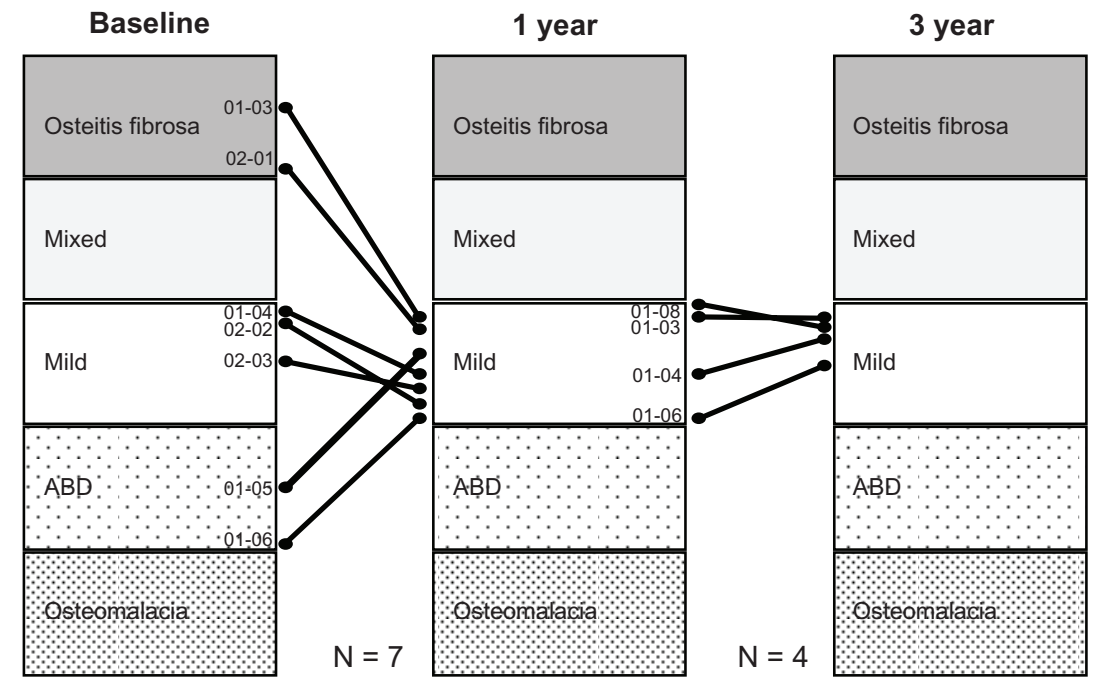

Figure 6 Effect of lanthanum carbonate treatment on bone in Japanese dialysis patients with hyperphosphatemia. In seven patients, pretreatment diagnosis was a fibrous osteitis-type disorder in two patients, a milder-type disorder in three patients, and an adynamic bone disease (ABD)-type disorder in two patients. After I year of treatment, the diagnosis changed to a milder-type disorder in all seven patients. After 3 years of treatment, bone biopsy was conducted on a total of four patients. The diagnosis of a milder-type disorder was maintained in all four patients. The results of histomorphometric analysis of cancellous bone showed that lanthanum carbonate treatment improved the osteoid condition toward normalization both in cases of excessive and cases of insufficient osteoid, and that the treatment also improved the resorption condition toward normalization in cases with both enhanced and reduced resorption.

Note: Copyright @ 201 I. Reproduced with permission from John Wiley and Sons. Shigematsu T, Tokumoto A, Nakaoka A, Arisaka H. Effect of lanthanum carbonate treatment on bone in Japanese dialysis patients with hyperphosphatemia. Ther Apher Dial. 201 I; I5(2):176-184.24 
A

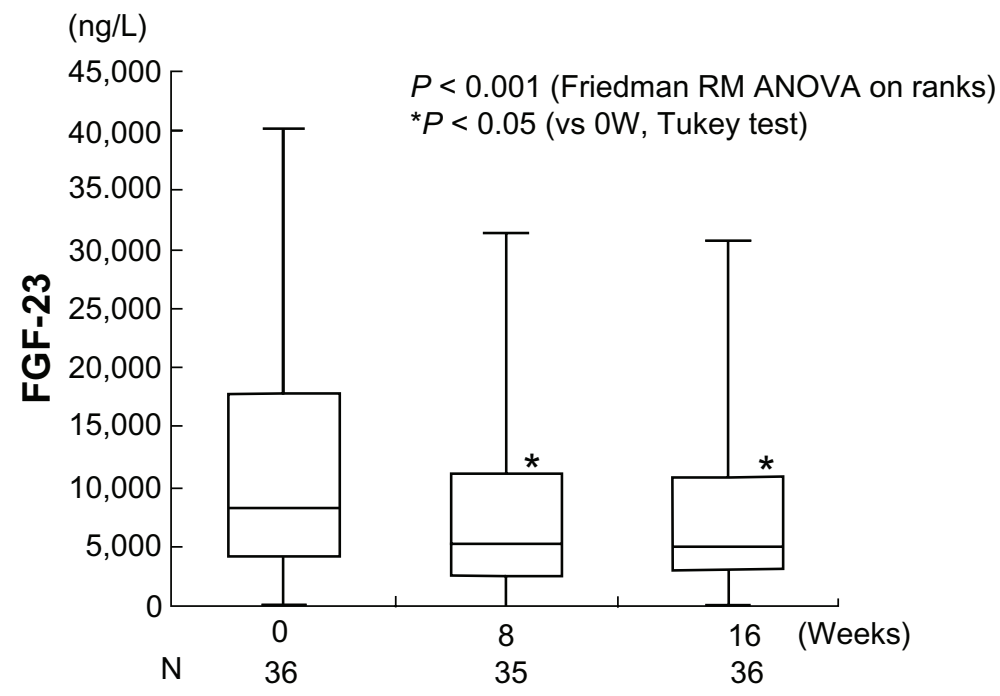

B

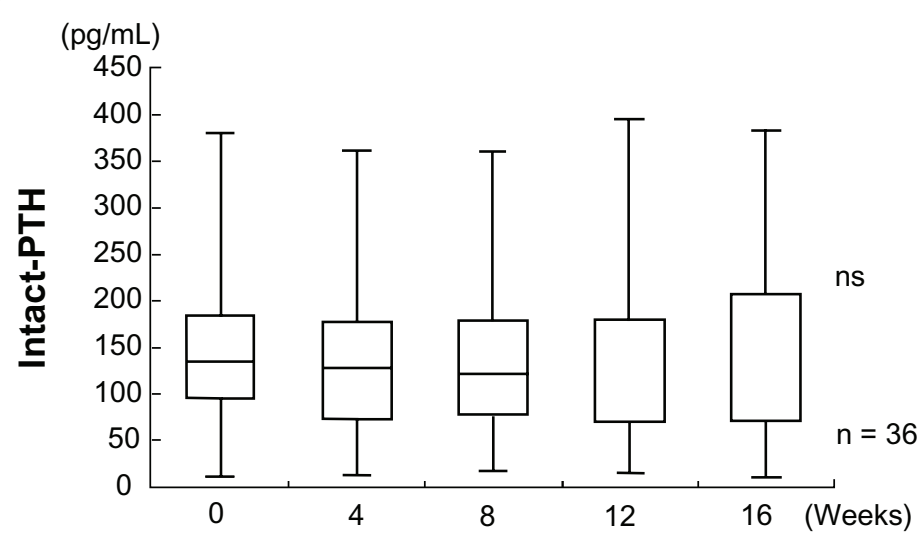

C

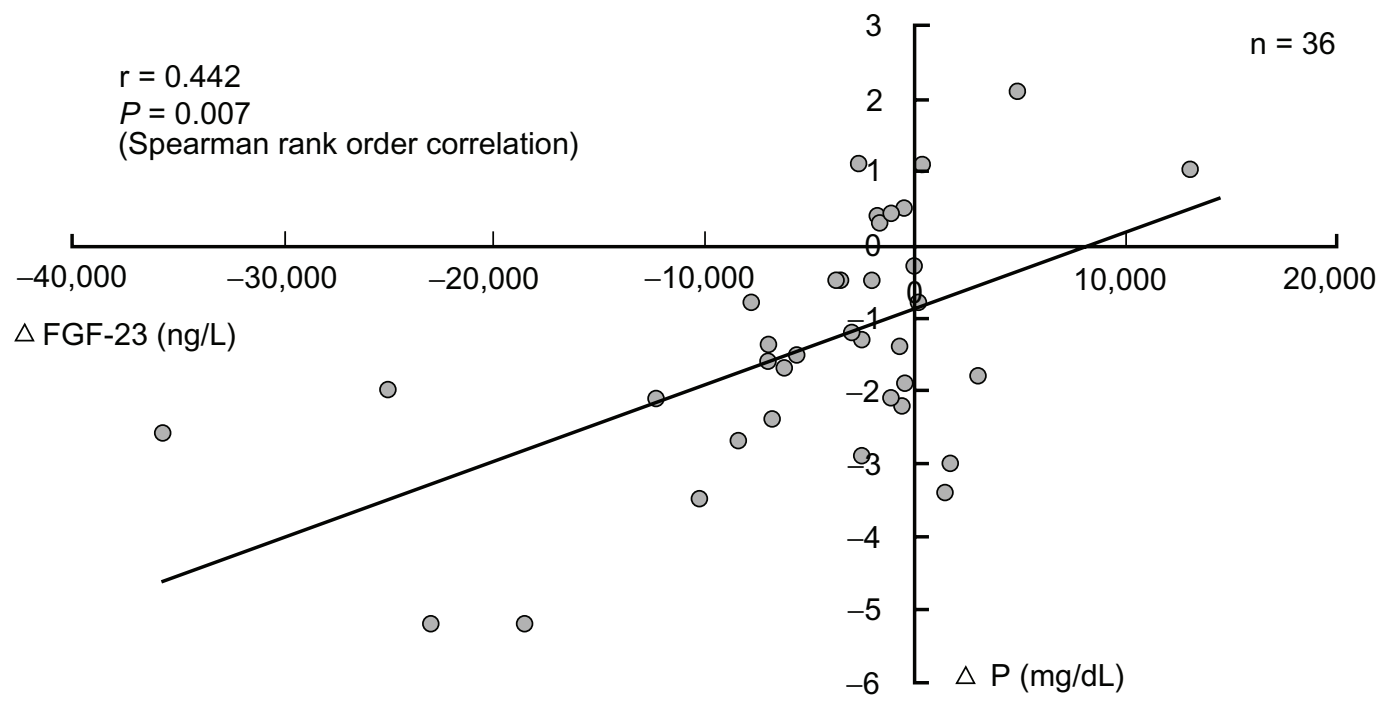

Figure 7 Combined therapy with lanthanum carbonate and calcium (Ca) carbonate for hyperphosphatemia decreases serum FGF23 levels independently of Ca and parathyroid hormone (PTH). The horizontal bar in each box indicates the median value. Upper and lower borders of the box are the 25th and 75th percentiles, respectively. Maximum and minimum values are shown by the vertical error bars. The significant $40 \%$ reduction of the circulating intact FGF23 level from baseline was observed after week 8 and week 16 of combined therapy of lanthanum carbonate and Ca carbonate therapy. On the other hand, the intact PTH level did not show any significant change within I6 weeks.

Note: Reproduced from Shigematsu T, Negi S; for the COLC Research Group. Combined therapy with lanthanum carbonate and calcium carbonate for hyperphosphatemia decreases serum FGF-23 level independently of calcium and PTH (COLC Study). Nephrol Dial Transplant. 20 I2;27(3): 1050-1054,32 with permission from Oxford Journals. 
carbonate and $\mathrm{Ca}$ carbonate for hyperphosphatemia in HD patients (Figure $7 \mathrm{~A}$ and B). ${ }^{32}$ In this study, the baseline FGF23 level was 8250 (115-40200) ng/L. It showed a significant decrease after week 8 and week 16 of add-on lanthanum carbonate therapy, decreasing to 5200 (38-31400) ng/L and 5000 (78-30700) ng/L, respectively. The authors measured intact FGF23 with a Kainos Laboratories assay kit (Kainos Laboratories, Inc, Tokyo, Japan), so the observed reduction of serum FGF23 levels was thought to directly reflect a reduction of FGF23 production in the bone. On the other hand, the baseline intact PTH was 134.7 (12.0-379.3) pg/mL, and it also showed no significant change during add-on lanthanum carbonate therapy. A significant correlation between reduction of the serum Pi and the change of serum FGF23 level was observed. As the reduction of serum Pi became more marked, the decrease of serum FGF23 also became greater (Figure 7C). ${ }^{32}$

Similar PTH-independent reduction of FGF23 by lanthanum carbonate has also been reported in CKD patients without HD therapy. ${ }^{33}$ The significant decrease of serum Pi level induced the reduction of serum FGF23. However, the clinical effect of this phenomenon is still unknown. A prospective, randomized, placebo-controlled study is required to answer this question.

\section{Precautions in X-ray examinations}

Lanthanum carbonate contains lanthanum, a typical lanthanide. Accordingly, it is detected as a contrast image in X-ray examinations. If tablets are swallowed, they are recognized as small disc shapes. When tablets are well chewed, they are quite often shown as contrast shadows in the stomach and intestinal tract. They are seen as clear contrast images in computerized tomography and dual energy X-ray absorptiometry scanning. ${ }^{34,35}$ The administration of lanthanum carbonate should be prohibited prior to X-ray imaging procedures.

\section{Therapeutic effect on calciphylaxis}

Calciphylaxis is a pathological illness of severe arteriolar calcification with internal occlusion and necrosis. The prognosis of this disease is poor. It has been reported that lanthanum carbonate was aggressively used for calciphylaxis in a patient with acute kidney injury, saving the life of the patient. ${ }^{31}$

\section{Inhibitory effect on vascular calcification}

Hyperphosphatemia is a risk factor for the progression of vascular calcification. ${ }^{2,14,37}$ It has been reported that the beneficial effect of lanthanum carbonate therapy for hyperphosphatemia may suppress vascular calcification. Toussaint et $\mathrm{al}^{38}$ reported that lanthanum carbonate was associated with reduced progression of aortic calcification compared with calcium carbonate in $30 \mathrm{HD}$ patients over 18 months. This interesting result should be observed by a prospective, large-scale, long-term clinical study. At present, a prospective, large-scale observational study (STudy Of hyperPhosphatemia in CKD5D patients undergoing HemoDialysis [STOP-HD trial]: UMIN-ID 000002002) to confirm the inhibitory effect of lanthanum carbonate on vascular calcification is progressing in Japan. Results of the study are awaited.

\section{Conclusion}

Hyperphosphatemia is an important complication and it may affect the prognosis of CKD patients. At present, many Pi-reduction drugs are under development. Lanthanum carbonate, a new class of non- $\mathrm{Ca} /$ non-aluminum $\mathrm{Pi}$ binder, shows potent effects in hyperphosphatemia management. No report as yet suggests real toxicity for bone and the CNS, which have caused concern. Clinical use of this compound will be explored. However, observations reported so far are short-term and none of them cover a period of more than 10 years. Thus, it appears that further detailed investigations are needed.

\section{Disclosure}

$\mathrm{T}$ Shigematsu has received honoraria as lecture fees from Bayer Yakuhin, Japan. However, the author has never had involvement that might raise the question of bias in the work reported or in the conclusions, implications, or opinions stated.

\section{References}

1. Tonelli M, Sacks F, Pfeffer M, Gao Z, Curhan G. Relation between serum phosphate level and cardiovascular event rate in people with coronary disease. Circulation. 2005;112(17):2627-2633. Erratum in: Circulation. 2007;116(23):e556.

2. Zheng CM, Lu KC, Wu CC, Hsu YH, Lin YF. Association of serum phosphate and related factors in ESRD-related vascular calcification. Int J Nephrol. 2011. Epub May 25, 2011.

3. Nakai S, Akiba T, Kazama J, et al. Effects of serum calcium, phosphorus, and intact parathyroid hormone levels on survival in chronic hemodialysis patients in Japan. Ther Apher Dial. 2008;12(1):49-54.

4. Block GA, Klassen PS, Lazarus JM, Ofsthun N, Lowrie EG, Chertow GM. Mineral metabolism, mortality, and morbidity in maintenance hemodialysis. J Am Soc Nephrol. 2004;15(8):2208-2218.

5. Kurihara S, Marumo F. Aluminum and iron deposition in dialysis patients. Nihon Rinsho. 1992;50 Suppl:905-910. Japanese.

6. Chertow GM, Burke SK, Raggi P; for Treat to Goal Working Group. Sevelamer attenuates the progression of coronary and aortic calcification in hemodialysis patients. Kidney Int. 2002;62(1):245-252.

7. Oka Y, Miyazaki M, Takatsu S, et al. Sevelamer hydrochloride exacerbates metabolic acidosis in hemodialysis patients, depending on the dosage. Ther Apher Dial. 2007;11(2):107-113. 
8. Pai AB, Shepler BM. Comparison of sevelamer hydrochloride and sevelamer carbonate: risk of metabolic acidosis and clinical implications. Pharmacotherapy. 2009;29(5):554-561.

9. Albaaj F, Hutchison AJ. Lanthanum carbonate for the treatment of hyperphosphataemia in renal failure and dialysis patients. Expert Opin Pharmacother. 2005;6(2):319-328.

10. Damment SJ, Shen V. Assessment of effects of lanthanum carbonate with and without phosphate supplementation on bone mineralization in uremic rats. Clin Nephrol. 2005;63(2):127-137.

11. Joy MS, Finn WF; for LAM-302 Study Group. Randomized, doubleblind, placebo-controlled, dose-titration, phase III study assessing the efficacy and tolerability of lanthanum carbonate: a new phosphate binder for the treatment of hyperphosphatemia. Am J Kidney Dis. 2003;42(1):96-107.

12. Shigematsu T; for Lanthanum Carbonate Research Group. Lanthanum carbonate effectively controls serum phosphate without affecting serum calcium levels in patients undergoing hemodialysis. Ther Apher Dial. 2008;12(1):55-61.

13. Kawanishi H, Ishida M, Ishizaki M, et al. Lanthanum carbonate treatment of patients with hyperphosphatemia undergoing CAPD. Perit Dial Int. 2008;28(6):673-675.

14. Shigematsu T, Kono T, Satoh K, et al. Phosphate overload accelerates vascular calcium deposition in end-stage renal disease patients. Nephrol Dial Transplant. 2003;18 Suppl 3:iii86-iii89.

15. Shigematsu T; for Lanthanum Carbonate Research Group. Multicenter prospective randomized, double-blind comparative study between lanthanum carbonate and calcium carbonate as phosphate binders in Japanese hemodialysis patients with hyperphosphatemia. Clin Nephrol. 2008;70(5):404-410.

16. Sprague SM, Ross EA, Nath SD, Zhang P, Pratt RD, Krause R. Lanthanum carbonate vs sevelamer hydrochloride for the reduction of serum phosphorus in hemodialysis patients: a crossover study. Clin Nephrol. 2009;72(4):252-258.

17. Hutchison AJ, Barnett ME, Krause R, Kwan JT, Siami GA; for SPD405309 Lanthanum Study Group. Long-term efficacy and safety profile of lanthanum carbonate: results for up to 6 years of treatment. Nephron Clin Pract. 2008;110(1):c15-c23. Erratum in: Nephron Clin Pract. 2008;110(1):c23.

18. Hutchison AJ, Barnett ME, Krause RJ, Siami GA; for Lanthanum Carbonate Study Group. Lanthanum carbonate treatment, for up to 6 years, is not associated with adverse effects on the liver in patients with chronic kidney disease Stage 5 receiving hemodialysis. Clin Nephrol. 2009;71(3):286-295.

19. Finn WF, Joy MS; for LAM-308 Study Group. A long-term, open-label extension study on the safety of treatment with lanthanum carbonate, a new phosphate binder, in patients receiving hemodialysis. Curr Med Res Opin. 2005;21(5):657-664.

20. Sprague SM. A comparative review of the efficacy and safety of established phosphate binders: calcium, sevelamer, and lanthanum carbonate. Curr Med Res Opin. 2007;23(12):3167-3175.

21. Shigematsu T; for Lanthanum Carbonate Research Group. Three-year extension study of lanthanum carbonate therapy in Japanese hemodialysis patients. Clin Exp Nephrol. 2010;14(6):589-597.

22. D'Haese PC, Spasovski GB, Sikole A, et al. A multicenter study on the effects of lanthanum carbonate (Fosrenol) and calcium carbonate on renal bone disease in dialysis patients. Kidney Int Suppl. 2003; 85:S73-S78
23. Malluche HH, Siami GA, Swanepoel C, et al. Improvements in renal osteodystrophy in patients treated with lanthanum carbonate for two years. Clin Nephrol. 2008;70(4):284-295.

24. Shigematsu T, Tokumoto A, Nakaoka A, Arisaka H. Effect of lanthanum carbonate treatment on bone in Japanese dialysis patients with hyperphosphatemia. Ther Apher Dial. 2011;15(2):176-184.

25. Behets GJ, Dams G, Vercauteren SR, et al. Does the phosphate binder lanthanum carbonate affect bone in rats with chronic renal failure? J Am Soc Nephrol. 2004;15(8):2219-2228.

26. Altmann P, Barnett ME, Finn WF; for SPD405-307 Lanthanum Carbonate Study Group. Cognitive function in Stage 5 chronic kidney disease patients on hemodialysis: no adverse effects of lanthanum carbonate compared with standard phosphate-binder therapy. Kidney Int. 2007;71(3):252-259.

27. Slatopolsky E, Liapis H, Finch J. Progressive accumulation of lanthanum in the liver of normal and uremic rats. Kidney Int. 2005;68(6): 2809-2813.

28. Ben-Dov IZ, Pappo O, Sklair-Levy M, et al. Lanthanum carbonate decreases PTH gene expression with no hepatotoxicity in uraemic rats. Nephrol Dial Transplant. 2007;22(2):362-368.

29. Bervoets AJ, Behets GJ, Schryvers D, et al. Hepatocellular transport and gastrointestinal absorption of lanthanum in chronic renal failure. Kidney Int. 2009;75(4):389-398.

30. Goto S, Komaba H, Moriwaki K, et al. Clinical efficacy and cost-effectiveness of lanthanum carbonate as second-line therapy in hemodialysis patients in Japan. Clin J Am Soc Nephrol. 2011;6(6): $1375-1384$.

31. Gutiérrez OM, Mannstadt M, Isakova T, et al. Fibroblast growth factor 23 and mortality among patients undergoing hemodialysis. $N$ Engl $J$ Med. 2008;359(6):584-592.

32. Shigematsu T, Negi S; for the COLC Research Group. Combined therapy with lanthanum carbonate and calcium carbonate for hyperphosphatemia decreases serum FGF-23 level independently of calcium and PTH (COLC Study). Nephrol Dial Transplant. 2012;27(3):1050-1054.

33. Gonzalez-Parra E, Gonzalez-Casaus ML, Galán A, et al. Lanthanum carbonate reduces FGF23 in chronic kidney disease stage 3 patients. Nephrol Dial Transplant. 2011;26(8):2567-2571.

34. Hayashi H, Machida M, Sekine T, Yamaguchi H, Kiriyama T, Kumita S. Beam-hardening artifacts on computed tomography images caused by lanthanum carbonate hydrate in a patient on dialysis. Jpn J Radiol. 2010;28(4):322-324.

35. Fürstenberg A, Buscombe J, Davenport A. Overestimation of lumbar spine calcium with dual energy X-ray absorptiometry scanning due to the prescription of lanthanum carbonate in patients with chronic kidney disease. Am J Nephrol. 2010;32(5):425-431.

36. Chan MR, Yevzlin AS, Hinshaw M, Jaffery JB. Calciphylaxis responsive to lanthanum carbonate (FOSRENOL) therapy. WMJ. 2008; 107(7):335-338

37. Mune S, Shibata M, Hatamura I, et al. Mechanism of phosphate-induced calcification in rat aortic tissue culture: possible involvement of Pit-1 and apoptosis. Clin Exp Nephrol. 2009;13(6):571-577.

38. Toussaint ND, Lau KK, Polkinghorne KR, Kerr PG. Attenuation of aortic calcification with lanthanum carbonate versus calcium-based phosphate binders in haemodialysis: a pilot randomized controlled trial. Nephrology (Carlton). 2011;16(3):290-298.

International Journal of Nephrology and Renovascular Disease

\section{Publish your work in this journal}

The International Journal of Nephrology and Renovascular Disease is an international, peer-reviewed open-access journal focusing on the pathophysiology of the kidney and vascular supply. Epidemiology, screening, diagnosis, and treatment interventions are covered as well as basic science, biochemical and immunological studies. The journal welcomes original research, clinical studies, reviews \& evaluations, expert opinion and commentary, case reports and extended reports. The manuscript management system is completely online and includes a very quick and fair peerreview system, which is all easy to use. Visit http://www.dovepress.com/ testimonials.php to read real quotes from published authors 